\title{
Humeral Rotational Osteotomy for Shoulder Deformity in Obstetric Brachial Plexus Palsy: Which Direction Should I Rotate?
}

\author{
Amr A. Abdelgawad* and Miguel A. Pirela-Cruz \\ Department of Orthopedic Surgery, Paul L. Foster School of Medicine, Texas Tech University Health Science Center at \\ El Paso, TX, USA
}

\begin{abstract}
Shoulder internal rotation contracture is the most common deformity affecting the shoulder in patients with Obstetric Brachial Plexus Palsy. With progression of the deformity, the glenohumeral joint starts to subluxate and then dislocates. This is accompanied with bony changes of both the humerus and the glenoid. Two opposite direction humeral osteotomies have been proposed for this condition (internal rotation osteotomy (IRO) and external rotation osteotomy (ERO)). This fact of different direction osteotomies has not adequately been explained in the literature. Most orthopedic surgeons may not be able to fully differentiate between these two osteotomies regarding the indications, outcomes and effects on the joint. This review explains these differences in details.
\end{abstract}

Keywords: Erb's Palsy, external rotation, glenohumeral joint, humeral osteotomy, internal rotation, internal rotation deformity, obstetric brachial plexus palsy (OBPP), shoulder dislocation.

\section{INTRODUCTION}

Obstetric brachial plexus palsy (OBPP) is an injury to the nerves of the upper extremity of the newborn that happens during labor. Erb's palsy $(\mathrm{C} 5,6)$ is the most common type of OBPP. Most of the infants with Erb's palsy will show spontaneous full recovery $[1,2]$. However, some of them will have residual weakness of shoulder's external rotation which will result in an internal rotation deformity of the affected shoulder in these children. If this internal rotation deformity is not repaired, it may progress to posterior dislocation of the shoulder joint with bony deformity of the glenoid [3].

The shoulder internal rotation deformity is treated surgically either by soft tissue release or by bony osteotomy. Traditionally, the osteotomy was done for older children with dislocated shoulders. The direction of the osteotomy was external rotation osteotomy. The purpose of the surgery was to improve the cosmetic and the function of the upper extremity. This osteotomy would ignore the deformity in the glenohumeral joint as it will actually result in more posterior dislocation of the humeral head in relation to the glenoid.

Recently, there have been articles describing internal rotation osteotomy for children who have Erb's palsy with internal rotation deformity and posterior shoulder dislocation. The aim of this osteotomy is to reduce the glenohumeral joint.

Articles and book chapter which described the osteotomies for shoulder deformity in Erb's palsy did not emphasize on the fact that there are two opposite direction osteotomies for the same condition which can cause great confusion among readers.

*Address correspondence to this author at the Department of Orthopedic surgery, Texas Tech University Health Science Center at El Paso, TX, 4801 Alberta Ave, El Paso, TX 79905, USA; Tel: 915-215-5407;

Fax: 915-545-6704; E-mail: amr.abdelgawad@ttuhsc.edu
The purpose of this article is to clarify these two opposite direction humeral osteotomies in cases of shoulder deformity as a result of OBPP, compare between these two types in regard to the indications, concepts and outcomes and to help the orthopedic surgeons identify the difference between these two osteotomies. Articles describing osteotomies for obstetric brachial palsy have been reviewed. Pubmed search has been conducted using "Erb's palsy", "obstetric brachial plexus palsy" together with osteotomy. Cross reference has also been used. In addition, pediatric orthopedic book chapters have been reviewed for their description of humeral osteotomies in cases of OBPP.

\section{DISCUSSION}

\section{Shoulder Pathology in Erb's Palsy}

Internal rotation contracture is the most frequent and important secondary deformity of the shoulder in children with Erb's palsy. It occurs due to weakness of the external rotators (teres minor and infraspinatus) muscles compared to the internal rotators (teres major, pectoralis major, latissimus dorsi) muscles. Because of the lack of external rotation and persistence of internal rotation, chronic posterior shoulder dislocation develops $[4,5]$. Children with Erb's palsy will develop secondary bone changes in the glenoid. Several authors have studied the shoulder pathology in cases of Erb's palsy [6-9]. Pearl et al. in 2003 [7], classified the glenoid deformity in patients with Erb's palsy using MRI, arthroscopy, and arthrography. According to their classification, the deformity of gleno-humeral articulation progressed from concentric, concentric posterior, flat, biconcave and pseudo glenoid (the latter is further subdivided into mild, moderate and severe). Waters et al. [9] classified the glenohumeral deformity with OBBP into seven grades (type I: normal articulation; type II: more than 5 retroversion of the glenoid with no subluxation; type III: posterior subluxation; type IV: progressive posterior humeral subluxation into a false 
glenoid; type V: severe flattening of the humeral head and glenoid, with progressive or complete posterior dislocation of the head; type VI: dislocation of the glenohumeral joint in infancy and type VII: growth arrest of the proximal aspect of the humerus).

The humeral shape is also affected by the internal rotation deformity. Over time the humeral head becomes retroverted, which Zancolli [5] describes as a posterior epiphysiolysis of the proximal humerus.

\section{Posterior Shoulder Dislocation in Infancy}

Some of the children with Erb's palsy will develop posterior dislocation early in their course of disease. This condition was thought to be rare, however, in the last two decades many publications about infantile posterior shoulder dislocations were made and have suggested that the onset of glenoid dysplasia which accompanies obstetric brachial plexus palsy occurs at an earlier age than what has been previously recognized and that the prevalence of this problem may have been underestimated [10-12].

Moukoko et al. in 2004 [10], studied 134 consecutive infants with neonatal brachial plexus palsy over a period of 2 years. Specific clinical signs associated with subluxation and dislocation were recorded. A rapid loss of passive external rotation between monthly examinations indicated a posterior shoulder dislocation. This was the main sign upon which they depended to diagnose posterior shoulder dislocation in infants with OBPP. Apparent shortening of the humeral segment of the involved extremity combined with asymmetrical skin folds indicates dislocation of the affected shoulder. The infants who were identified as having these clinical signs were evaluated with ultrasonographic imaging studies. Eleven $(8 \%)$ of the 134 infants had a posterior shoulder dislocation. The mean age at the time of diagnosis was six months (range, three to ten months). There was no correlation between the occurrence of dislocation and the type of initial neurological deficit.

\section{External Rotational Osteotomy (ERO)}

This type of osteotomy has been reported by many authors [13-20] and also described in the pediatric orthopedic textbooks $[21,22]$. It is usually performed in older children with advanced shoulder deformity. The osteotomy is performed to increase the range of external rotation of the affected shoulder. The effect of osteotomy on the glenohumeral joint is that it actually increases the posterior dislocation of the humeral head. The head of the humerus sits at a more posterior dislocated position.

This osteotomy has been the standard of treatment in older children. The results of this osteotomy have been very satisfying with improvement of both external rotation and, to a lesser degree, abduction of the shoulder joint. Improvement of abduction has been attributed to a better mechanical alignment of the deltoid muscle. On the other hand, there is always some loss of internal rotation with this procedure (manifested by the child not able to reach his/her abdomen by his/her hand).

The osteotomy is usually performed proximal to the level of deltoid tuberosity to improve the alignment of the deltoid. Some authors have recommended adding flexion of the distal part of the humerus to cause an increase in elevation of the arm [14]. Others have recommended adding varus component to repair the abduction contracture [18]. External immobilization is usually not needed if the osteotomy is fixed with plates and screws. Tables $\mathbf{1}$ and $\mathbf{2}$ show pre and ostoperative range of motion for some studies which used ERO. Fig. (1) is an example of ERO.

\section{Internal Rotation Osteotomy (IRO)}

Internal rotation osteotomy has rarely been reported in the literature $[23,24]$. It is described in young children who develop posterior dislocation of the shoulder early in their

Table 1. Results of ERO by degrees of ROM.

\begin{tabular}{|c|c|c|c|c|c|c|c|}
\hline Study & \multicolumn{3}{|c|}{ External Rotation } & \multicolumn{3}{|c|}{ Abduction } & Remarks \\
\hline Kirkos and Papadopoulos [19] & -41 & 24.5 & 65.5 & 93 & 120 & 27 & \\
\hline Waters and Bae [18] & -14 & 16 & 64 & & & & \\
\hline Abdelgawad [20] & -27 & 28 & 55 & 132 & 140 & 8 & \\
\hline
\end{tabular}

Table 2. Showing the results of preoperative and postoperative Mallet score [26] for the studies using ERO.

\begin{tabular}{|c|c|c|c|c|c|c|c|c|}
\hline & \multicolumn{4}{|c|}{ Preoperative } & \multicolumn{4}{c|}{ Postoperative } \\
\cline { 2 - 9 } & Abd & Ext Rot & Hand to Nape & Hand to Mouth & Abd & Ext Rot & Hand to Nape & Hand to Mouth \\
\hline \hline Waters and Bae [18] & & 2 & 3 & 3 & & 4 & 4 & 4 \\
\hline Abzug et al. [13] & 3.5 & 2.4 & 2.5 & 2.6 & 3.7 & 3.3 & 3.1 & 3.6 \\
\hline Abdelgawad [20] & 4 & 1.1 & 1.9 & 2 & 4 & 3.1 & 3 \\
\hline
\end{tabular}



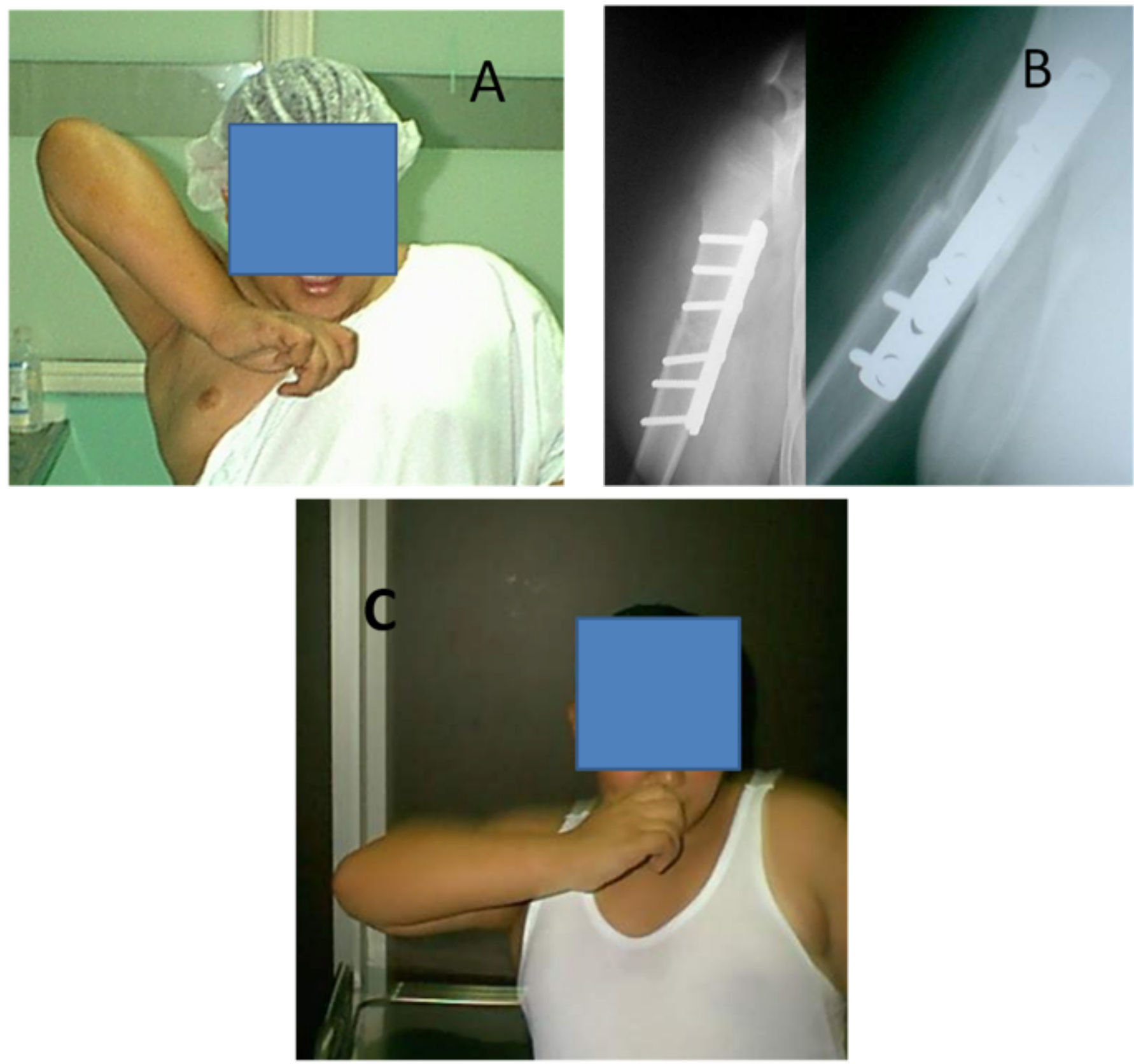

Fig. (1). Shows a 12 years old boy with severe right shoulder internal rotation deformity. A: Severe internal rotation deformity with the patient having to put his elbow above the shoulder level in order for the hand to reach the mouth. B: 6 weeks postoperative AP and LAT radiographs of ERO fixed with plates and screws. C: 6 months follow up; notice the improvement of the upper extremity position when the child puts his hand over the mouth.

course of disease. The internal rotation osteotomy is performed to reduce the glenohumeral joint. However, this osteotomy is likely to result in more loss of external rotation (loss of external rotation associated with internal rotation contracture in addition to loss of external rotation associated with the internal rotation osteotomy). In order to restore the external rotation of the shoulder in these children, this procedure has to be combined with process of release of the internal rotators muscles and the anterior capsule (Sever's operation [25]) with the possible need for transfer of internal rotators to act as external rotators.

Sibinski and Synder [23] described internal rotation osteotomy (IRO) with tendon transfer. They started first with soft tissue procedures and then checked the arc of motion. In cases where humeral head was dislocated in internal rotation, the IRO of proximal humerus was done to improve joint stability. Ten patients out of 25 needed the IRO. They found that active internal rotation difference in children treated with IRO was significantly higher than that in those treated without osteotomy. The other movements (including external rotation) were similar before and after surgery in both groups. The authors concluded that the addition of IRO to soft tissue procedures around the shoulder allows better internal rotation and maintains stable reduction without compromising other movements. 
Table 3. The difference between ERO and IRO.

\begin{tabular}{|c|c|c|}
\hline Indication & $\begin{array}{l}\text { Deformed glenoid (Waters VI, V, VI } \\
\text { or Pearls "pseudoglenoid") }\end{array}$ & $\begin{array}{l}\text { Posterior dislocation of the shoulder with relatively } \\
\text { normal glenoid } \\
\text { Increase humeral retroversion } \\
\text { Unstable shoulder joint after reduction of the } \\
\text { glenohumeral joint and performing anterior shoulder } \\
\text { release }\end{array}$ \\
\hline Effect on the glenohumeral joint & Increase the deformity of the joint & Reduce the dislocated joint \\
\hline Effect of humeral retroversion & Increase the humeral retroversion & Decrease the humeral retroversion \\
\hline Effect on the range of shoulder external rotation & Increase & Decrease \\
\hline
\end{tabular}

Similarly, Kambhampati et al. [24] prospectively studied 183 consecutive cases of subluxation (101) and dislocation (82) of the shoulder secondary to obstetric brachial plexus palsy between 1995 and 2000. Authors did anterior release and relocation then they measured the degree of retroversion. They performed IRO if the humerus was retroverted more than $40^{\circ}$ or if the head was particularly unstable after relocation. This procedure was necessary in 70 of the 183 shoulders.

Table 3 shows the difference between ERO and IRO.

\section{CONCLUSION}

Both external rotation osteotomy (ERO) and internal rotation osteotomy (IRO) have a role in the management of shoulder deformity in patients with obstetric brachial plexus palsy. Each osteotomy has its indication, effect on the glenohumeral joint and effect on the child's shoulder range of movement. Pediatric orthopedic surgeons treating these children should understand the difference between these two opposite direction osteotomies. They should decide which osteotomy the patient needs and plan the appropriate surgery according to the condition of the patient.

\section{CONFLICT OF INTEREST}

The authors confirm that this article content has no conflicts of interest.

\section{ACKNOWLEDGEMENTS}

Declared none.

\section{REFERENCES}

[1] Greenwald AG, Schute PC, Shiveley JL. Brachial plexus birth palsy: a 10-year report on the incidence and prognosis. J Pediatr Orthop 1984; 4: 689-92.

[2] Abdelgawad A, Naga O. Birth injuries and orthopedic manifestations in newborns. In: Pediatric Orthopedics: Handbook for primary care physicians. Abdelgawad A and Naga O, Eds. Springer New York 2014; pp. 75-83.

[3] Hoeksma AF, Ter Steeg AM, Dijkstra PF, Nelissen RG, Beelen A, de Jong BA. Shoulder contraction and bony deformity in obstetrical brachial plexus injury. J Bone Joint Surg 2003; 85A: 316-22.

[4] Zancolli EA. Classification and management of the shoulder in birth palsy. Orthop Clin North Am 1981; 12: 433-57.

[5] Zancolli EA, Zancolli ER III. Reconstructive surgery in brachial plexus sequelae. In: The Growing hand. Gupta A, Kay SPJ, Scheker LR, Eds. 2000; London, UK: Mosby, pp. 805-23.

[6] Pearl ML, Edgerton BW. Glenoid deformity secondary to brachial plexus birth palsy. J Bone Joint Surg 1998; 80A: 659-67.

[7] Pearl ML, Edgerton BW, Kon DS, et al. Comparison of arthroscopic findings with magnetic resonance imaging and arthrography in children with glenohumeral deformities secondary to brachial plexus birth palsy. J Bone Joint Surg 2003; 85A: 89098.

[8] Saifuddin A, Heffernan G, Birch R. Ultrasound diagnosis of shoulder congruity in chronic obstetric brachial plexus palsy. J Bone Joint Surg 2002; 84B: 100-3.

[9] Waters PM, Smith GR, Jaramillo D. Glenohumeral deformity secondary to brachial plexus birth palsy. J Bone Joint Surg 1998; 80A: 668-77.

[10] Moukoko D, Ezaki M, Wilkes D, Carter P. Posterior shoulder dislocation in infants with neonatal brachial plexus palsy. J Bone Joint Surg 2004; 86B: 787-93

[11] Troum S, Floyd WE 3rd, Waters PM. Posterior dislocation of the humeral head in infancy associated with obstetrical paralysis. A case report. J Bone Joint Surg 1993; 75A: 1370-5.

[12] Torode I, Donnan L. Posterior dislocation of the humeral head in association with obstetric paralysis. J Pediatr Orthop 1998; 18: 6115.

[13] Abzug JM, Chafetz RS, Gaughan JP, Ashworth S, Kozin SH Shoulder function after medial approach and derotational humeral osteotomy in patients with brachial plexus birth palsy. J Pediatr Orthop 2010; 30(5): 469-74.

[14] Al-Zahrani S. Combined Sever's release of the shoulder and osteotomy of the humerus for Erb's palsy. J Hand Surg Br 1997; 22: 591-593.

[15] Al-Qattan MM. Total obstetric brachial plexus palsy in children with internal rotation contracture of the shoulder, flexion contracture of the elbow, and poor hand function: improving the cosmetic appearance of the limb with rotation osteotomy of the humerus. Ann Plast Surg 2010; 65(1): 38-42.

[16] Al-Qattan MM, Al-Husainan H, Al-Otaibi A, El-Sharkawy MS. Long-term results of low rotation humeral osteotomy in children with Erb's obstetric brachial plexus palsy. J Hand Surg Eur Vol 2009; 34(4): 486-92. 
[17] Al-Qattan MM. Rotational osteotomy of the humerus for Erb's palsy in children with humeral head deformity. J Hand Surg Am 2002; 27: 479-83.

[18] Waters PM, Bae DS. The effect of derotational humeral osteotomy on global shoulder function in brachial plexus birth palsy. J Bone Joint Surg Am 2006; 88: 1035-42.

[19] Kirkos JM, Papadopoulos IA. Late treatment of brachial plexus palsy secondary to birth injuries: rotational osteotomy of the proximal part of the Humerus. J Bone Joint Surg Am 1998; 80A: 1477-83.

[20] Abdelgawad AA. Shoulder deformity in children with Erb's palsy. Dissertation. Faculty of Medicine, Ain Shams University 2005.

[21] Tachdjian MO. Neck-Shoulder. In: Tachdjian M, Ed. Atlas of pediatric orthopaedics, Philadelphia, USA: Saunders, 1994; pp: $1-78$.
[22] Waters PM. The upper limb. In: Morrissy RT, Weinstein SL, Eds. Lovell \& Winter's pediatric orthopaedics. $6^{\text {th }}$ ed. USA: Lippincott Williams \& Wilkins 2005; pp. 922-85.

[23] Sibiński M, Synder M. Soft tissue rebalancing procedures with and without internal rotation osteotomy for shoulder deformity in children with persistent obstetric brachial plexus palsy. Arch Orthop Trauma Surg 2010; 130(12): 1499-504.

[24] Kambhampati SBS, Birch R, Cobiella C, Chen L. Posterior subluxation and dislocation of the shoulder in obstetric brachial plexus palsy. J Bone Joint Surg Br 2006; 88-B: 213-9.

[25] Sever JW. Obstetric paralysis. A report of 470 cases. Am J Dis child 1916; 12: 541-78.

[26] Mallet J. Paralysie obsietricale du plexus brachial, Traitement des sequelles (French). Rev Chir Orthop 1972; 55(Suppl): 166-8.

(C) Abdelgawad and Pirela-Cruz; Licensee Bentham Open.

This is an open access article licensed under the terms of the Creative Commons Attribution Non-Commercial License (http://creativecommons.org/licenses/by-nc/3.0/) which permits unrestricted, non-commercial use, distribution and reproduction in any medium, provided the work is properly cited. 